\title{
Self-standing N-doped carbonized cellulose fiber as a dual-functional host for lithium metal anodes
}

Zhipeng Wen ${ }^{a}$, Huiyang Li ${ }^{a}$, Jiaxiang Liu ${ }^{b}$, Yang Yang ${ }^{*}$ and Jinbao Zhao ${ }^{\text {* }}$

a State Key Lab of Physical Chemistry of Solid Surfaces, Collaborative Innovation Centre of Chemistry for Energy Materials, State-Province Joint Engineering Laboratory of Power Source Technology for New Energy Vehicle, Engineering Research Center of Electrochemical Technology, Ministry of Education, College of Chemistry and Chemical Engineering, Xiamen University, Xiamen, 361005, P.R. China.

${ }^{\mathrm{b}}$ College of Energy \& School of Energy Research, Xiamen University, Xiamen 361102 , Fujian, China.

c School of Chemical Engineering and Light Industry, Guangdong University of Technology, Guangzhou 510006, China.

E-mail:

yangyang@gdut.edu.cn;

jbzhao@xmu.edu.cn

The number of pages: 10

The number of figures: 12

The number of tables: 4 

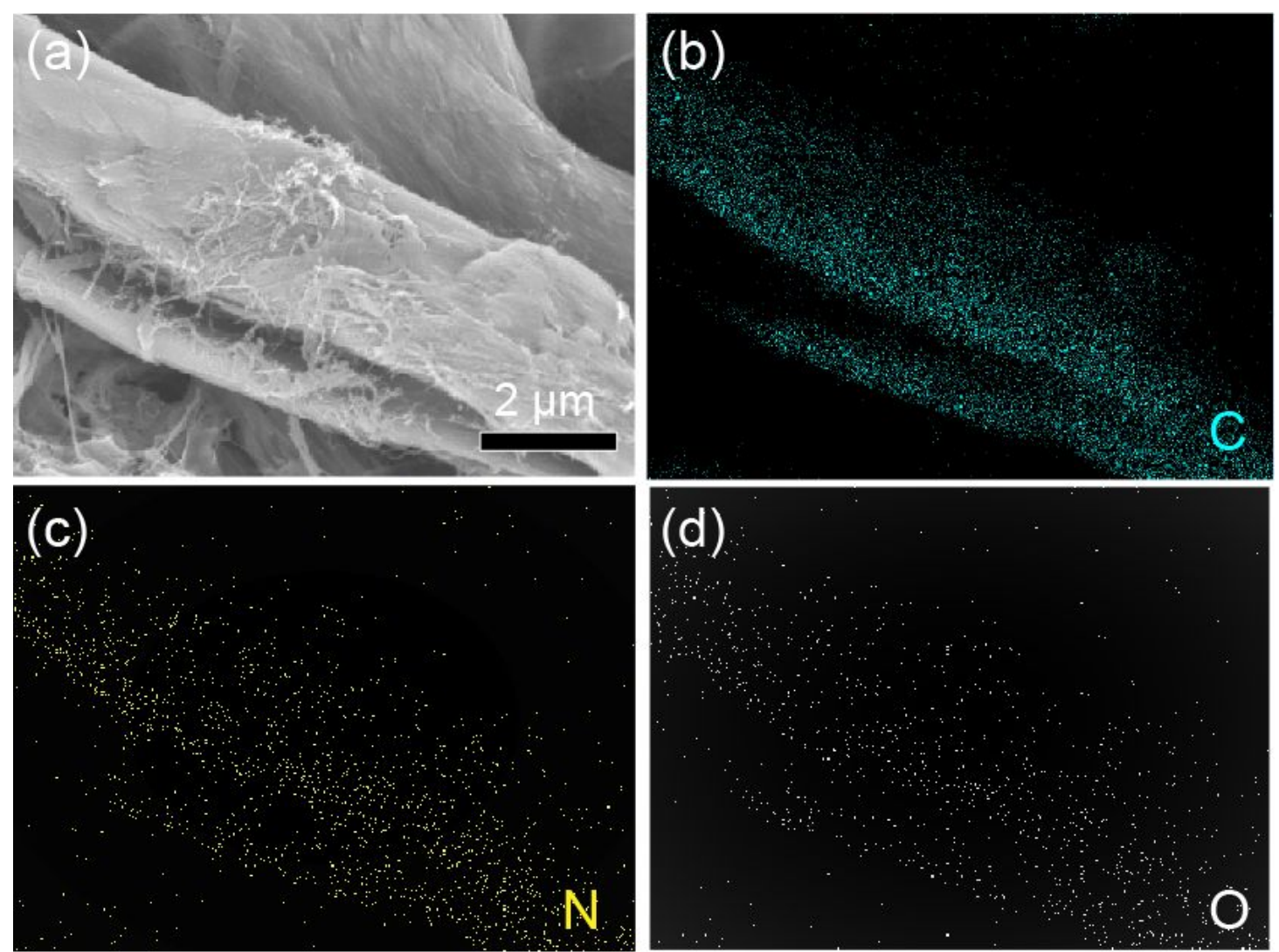

Figure S1. The (a) SEM image and corresponding (b) C element, (c) N element and (d) O element mapping of the N-CF current collector. 

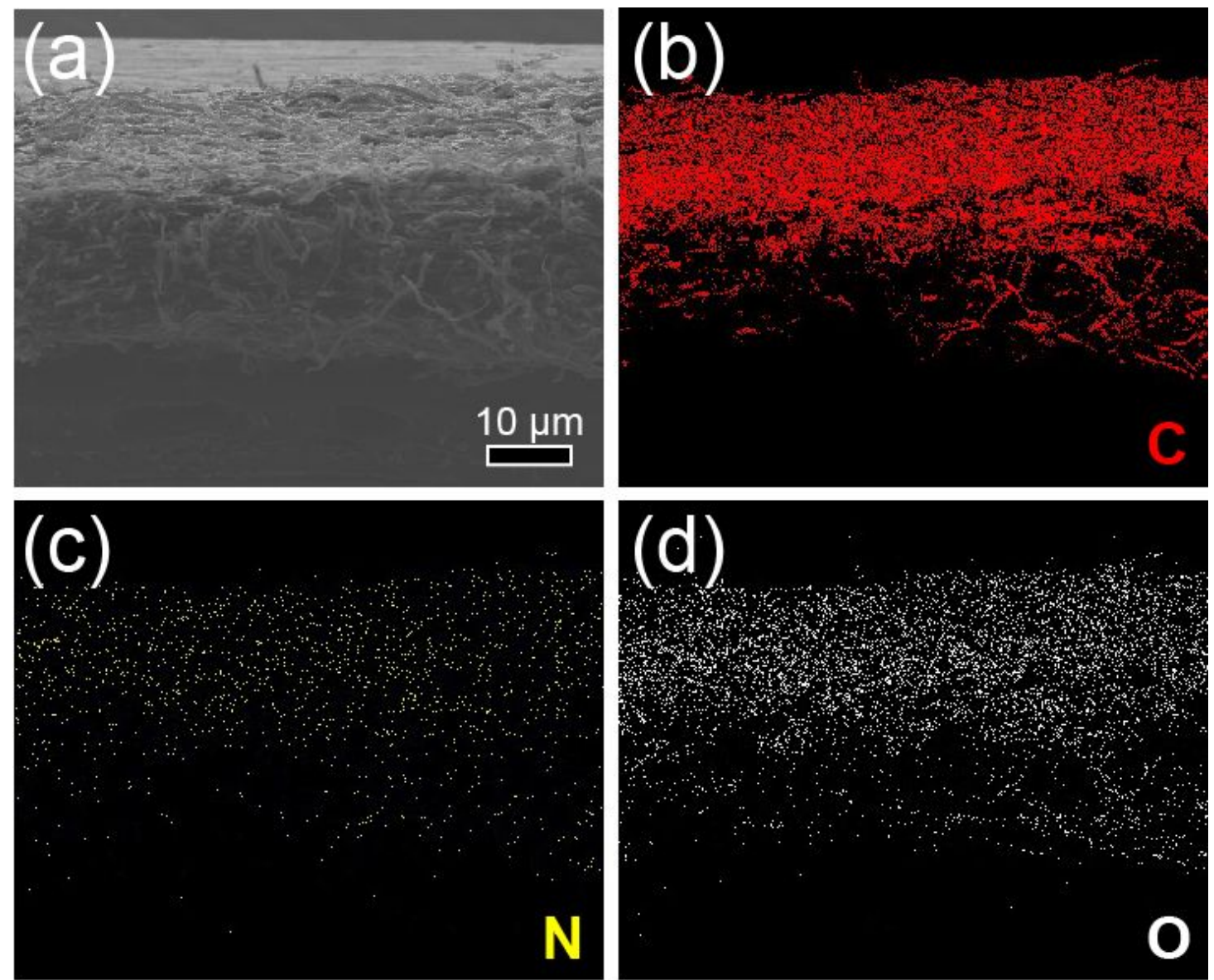

Figure S2. The cross-section (a) SEM image and (b) C element, (c) N element and (d)

$\mathrm{O}$ element distribution of N-CF current collector.
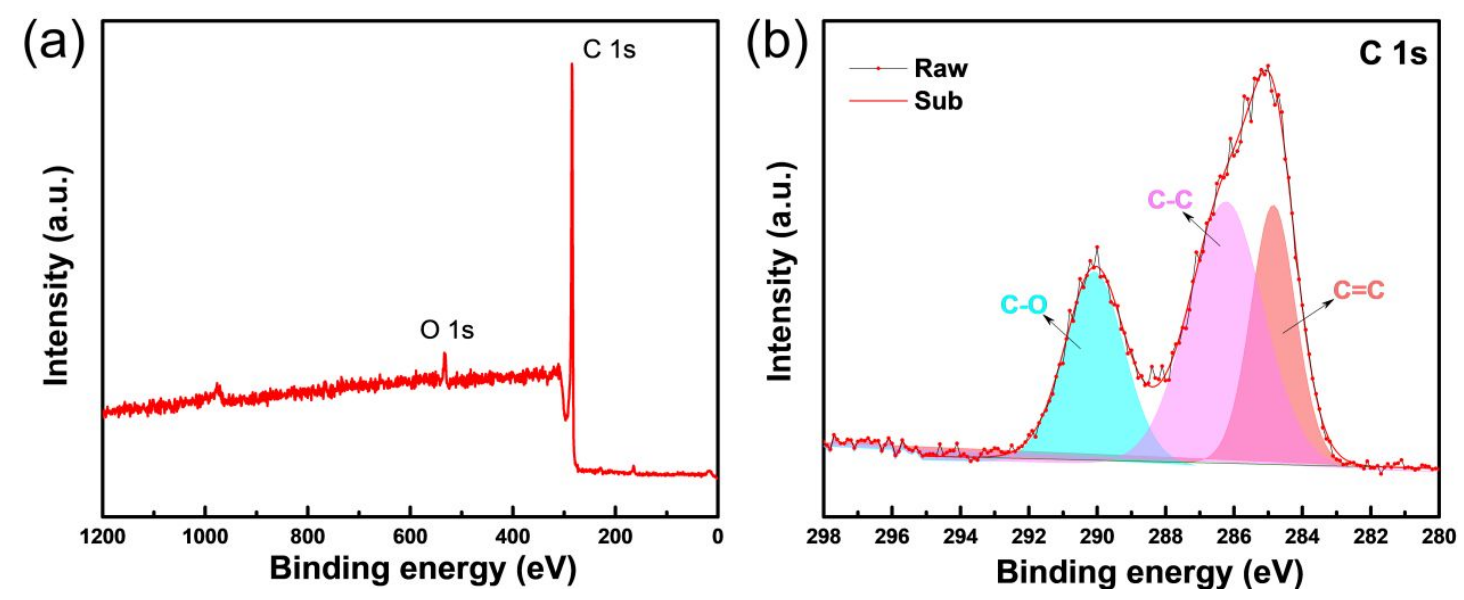

Figure S3. The (a) XPS spectra and (b) C 1s spectra of N-CF current collector. 

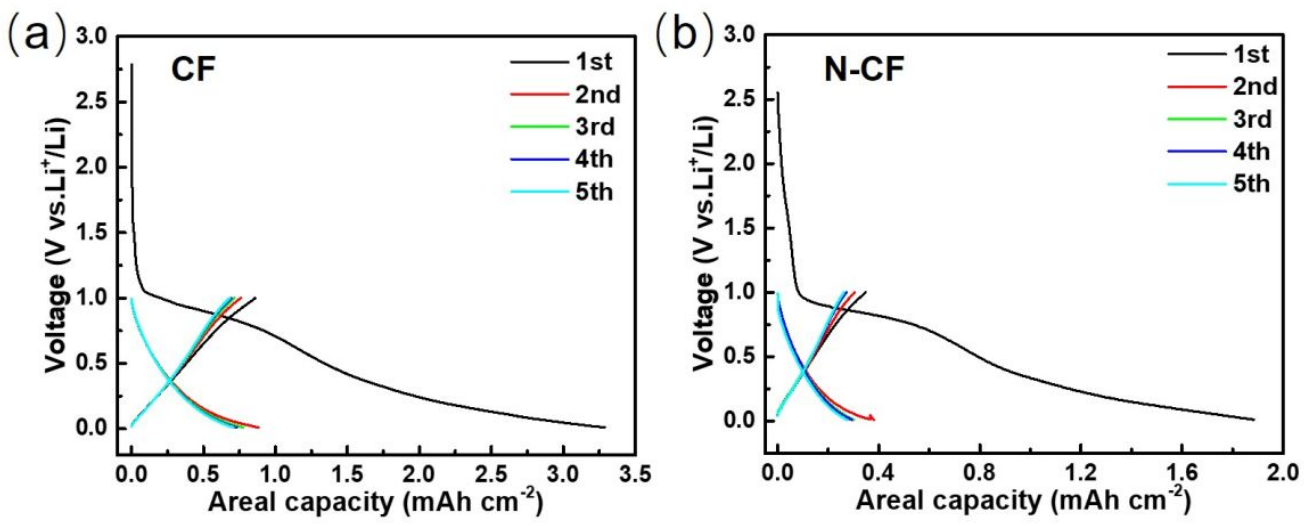

Figure S4. The detailed voltage-capacity spectra of (a) CF and (b) N-CF at activation process

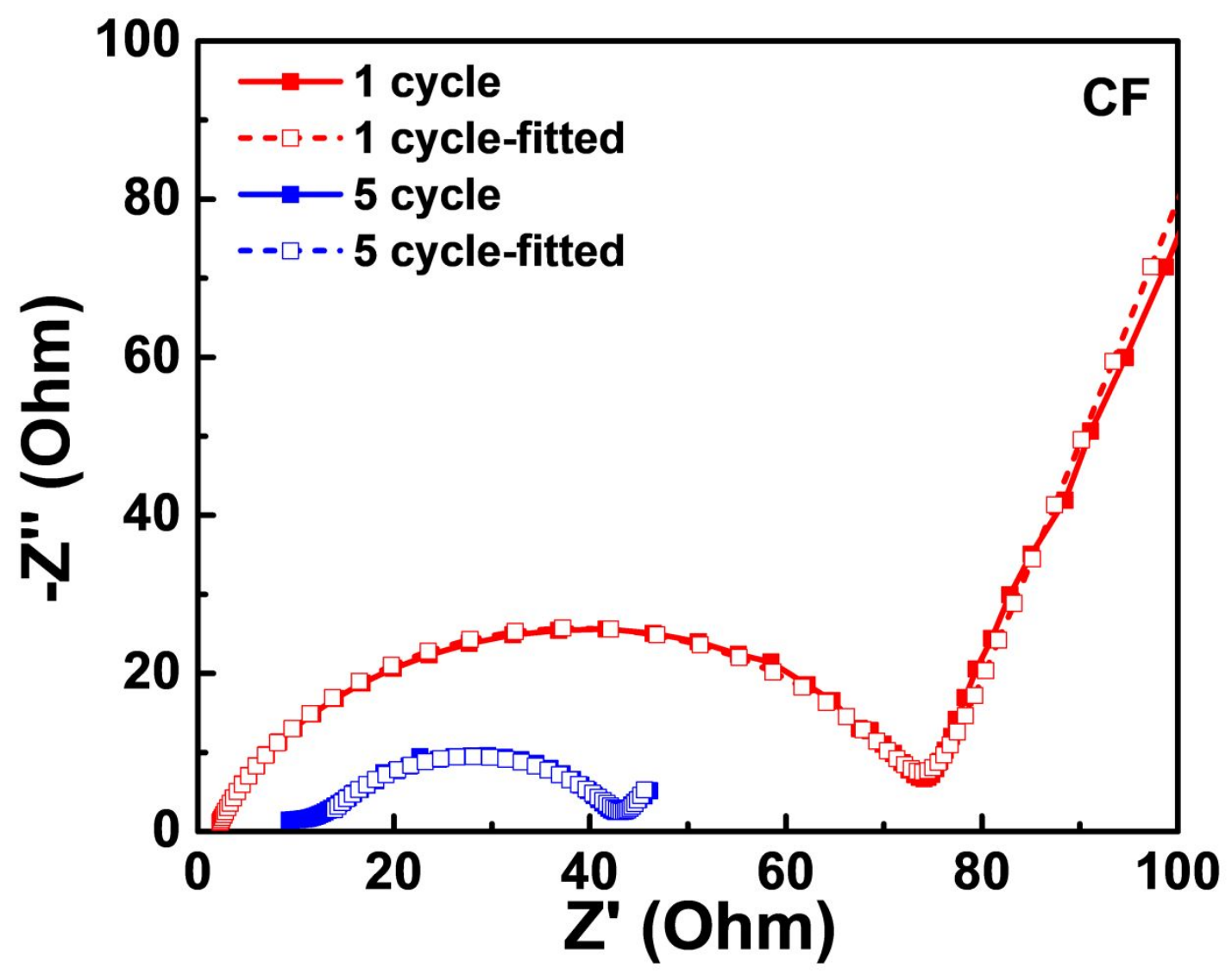

Figure S5. The enlarged EIS spectra of CF after 5 cycles. 
(a)

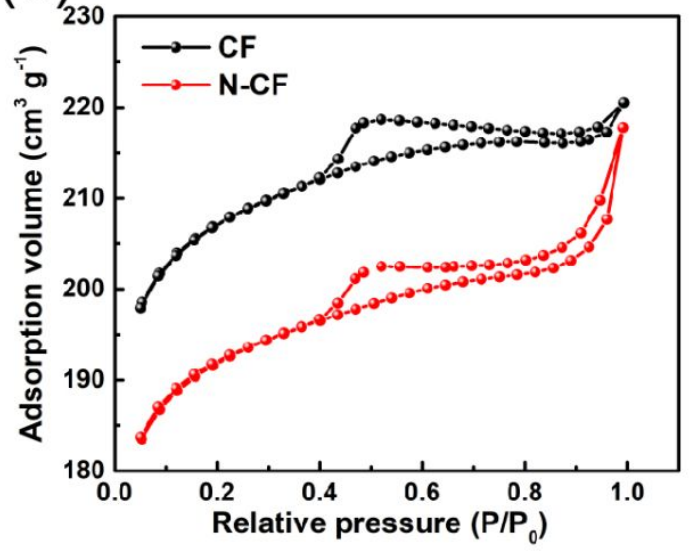

(b)

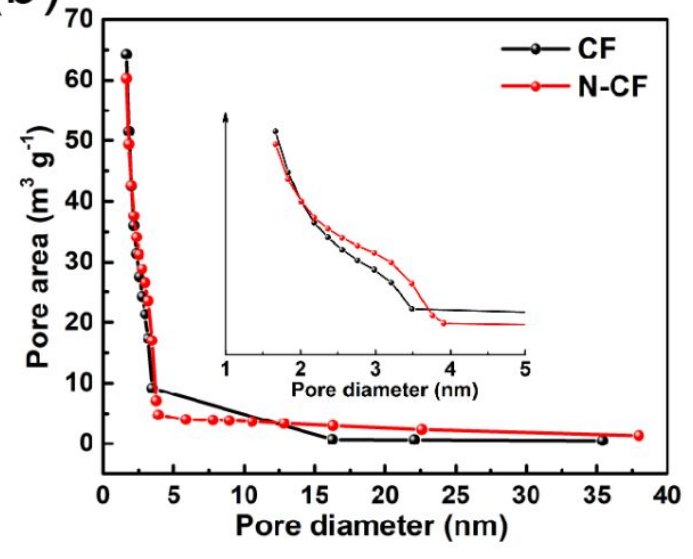

Figure S6. The (a) nitrogen adsorption-desorption isotherms and (b) pore area distribution of $\mathrm{CF}$ and $\mathrm{N}-\mathrm{CF}$ current collector.
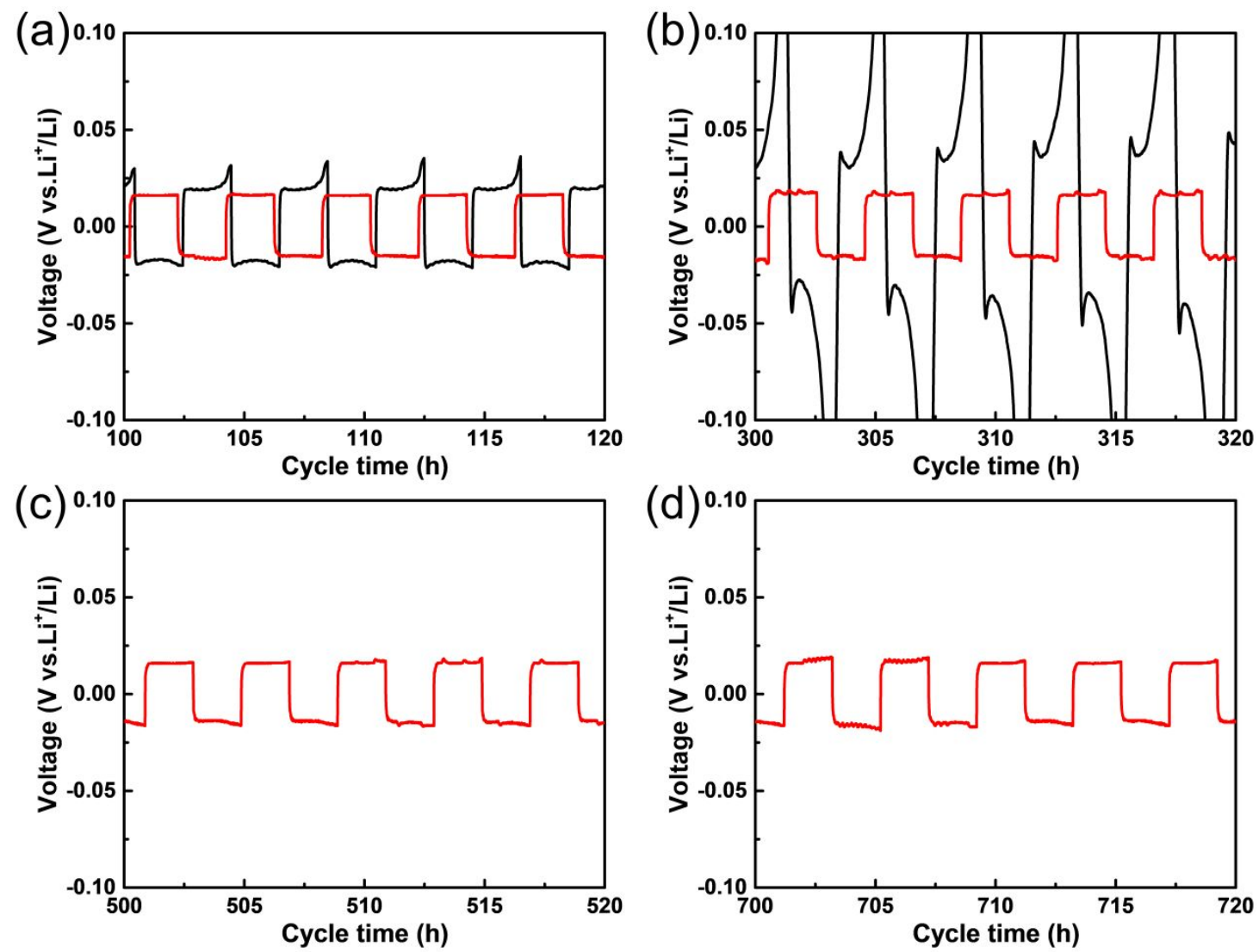

Figure S7. The enlarged voltage profiles of symmetric Li metal cell after (a) $100 \mathrm{~h}$,

(b) $300 \mathrm{~h}$, (c) $500 \mathrm{~h}$ and (d) $700 \mathrm{~h}$. 

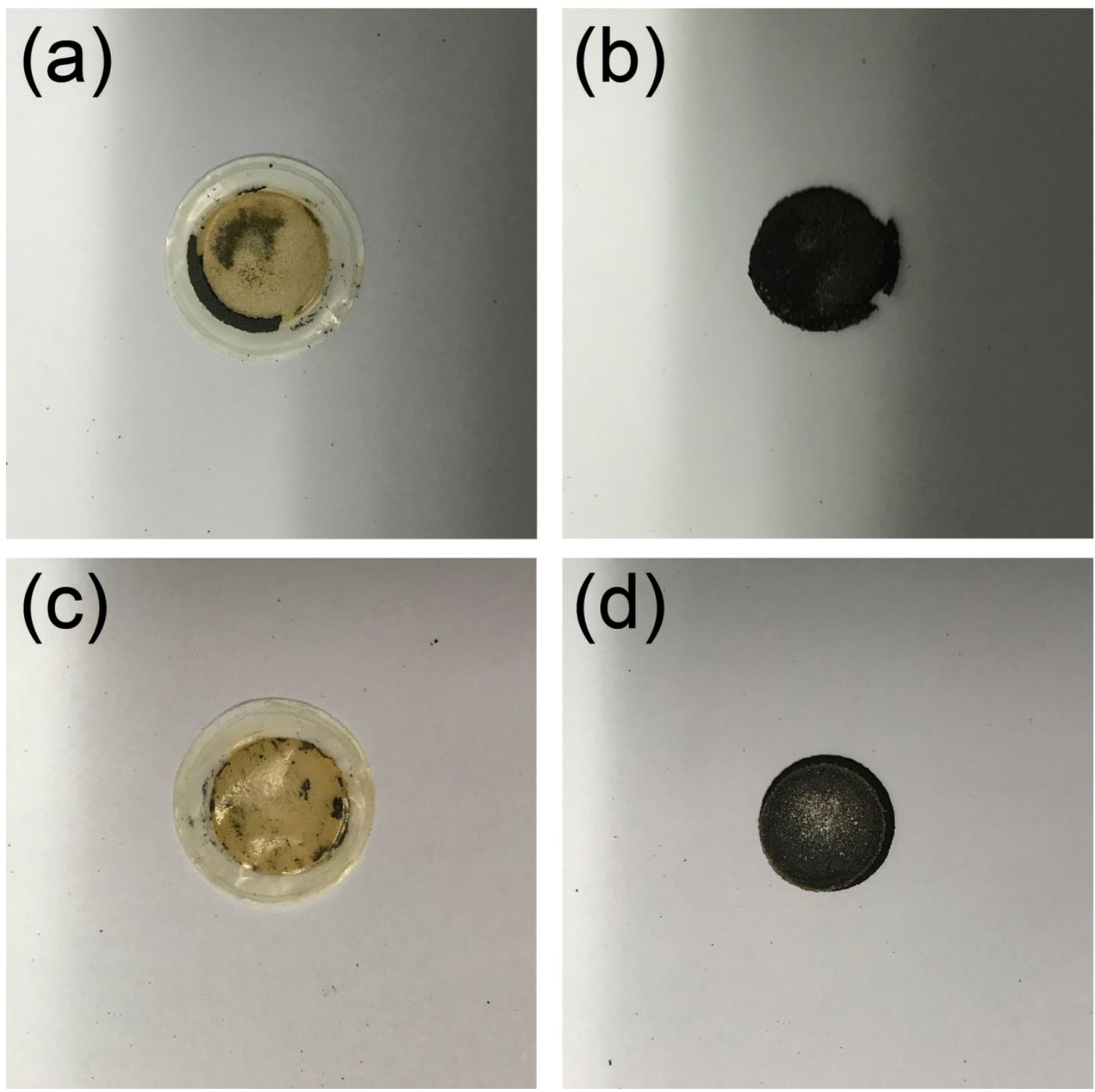

Figure S8. The photograph comparison of (a, b) CF and (c, d) N-CF current collector after 30 cycles with current density of $1 \mathrm{~mA} \mathrm{~cm}^{-2}$.
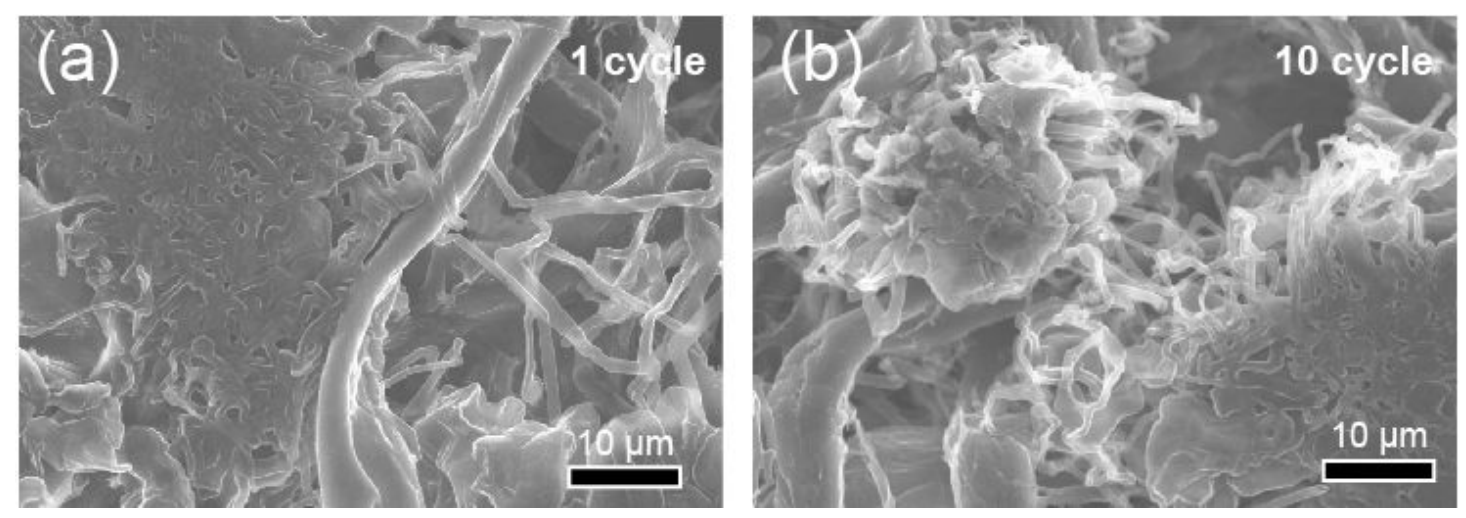

Figure S9. The detailed SEM images of Li deposition morphology with CF current collector after (a) 1 cycle and (b) 10 cycles. 

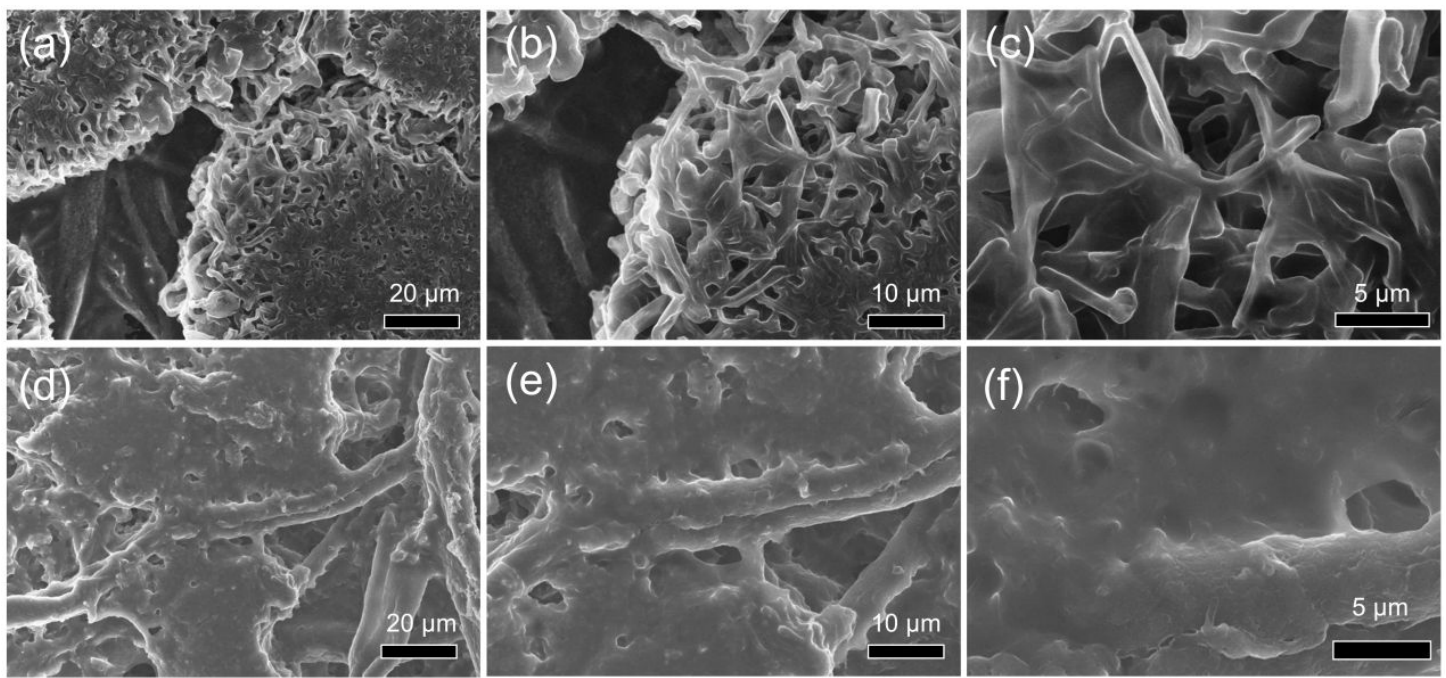

Figure S10. The different magnification SEM figures of Li metal morphologies with

CF (a-c) and N-CF (d-f) current collector when deposited $10 \mathrm{mAh} \mathrm{cm}^{-2} \mathrm{Li}_{\text {metal. }}$

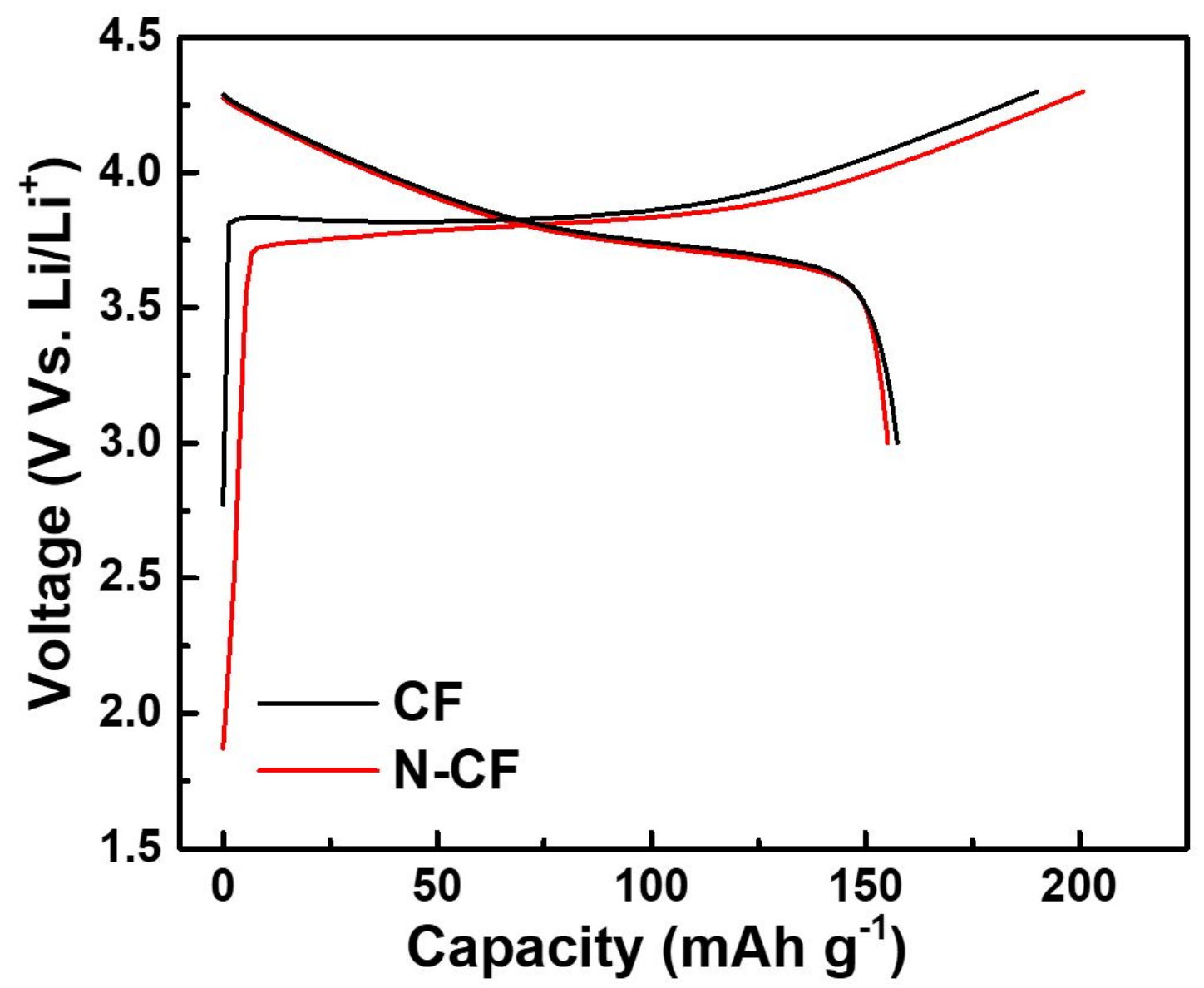

Figure S11. The enlarged voltage profile of CF and N-CF electrode at first cycle. 


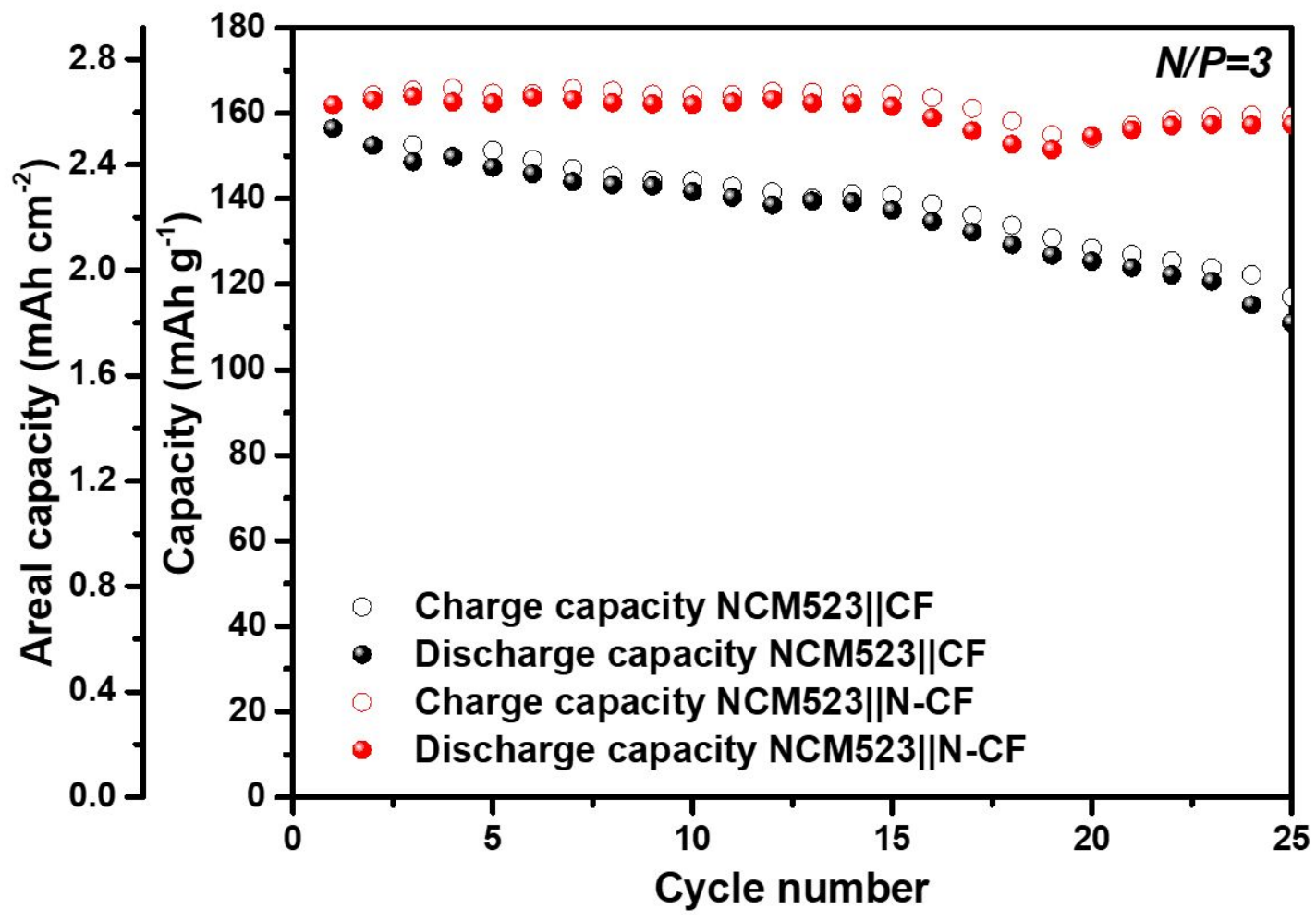

Figure S12. The tests of Li $\|$ NCM523 full cells at $1.0 \mathrm{C}$ with capacity ratios of anode/cathode of 3 (NCM loading of $16.254 \mathrm{mg} \mathrm{cm}^{-2}$ ). 
Table S1. The physical properties of CF and N-CF current collector

\begin{tabular}{ccc}
\hline & CF & N-CF \\
\hline Thickness & $0.272 \mathrm{~mm}$ & $0.320 \mathrm{~mm}$ \\
Weight & $5.36 \mathrm{mg}$ & $6.31 \mathrm{mg}$ \\
\hline
\end{tabular}

Table S2. The specific capacity of composite anode with CF and N-CF host

\begin{tabular}{|c|c|c|}
\hline Li metal deposition & CF & $\mathbf{N}-\mathbf{C F}$ \\
\hline $3 \mathrm{mAh} \mathrm{cm}^{-2}$ & $489 \mathrm{mAh} \mathrm{g}^{-1}$ & $423 \mathrm{mAh} \mathrm{g}^{-1}$ \\
\hline $5 \mathrm{mAh} \mathrm{cm}^{-2}$ & $751 \mathrm{mAh} \mathrm{g}^{-1}$ & $657 \mathrm{mAh} \mathrm{g}^{-1}$ \\
\hline $7.8 \mathrm{mAh} \mathrm{cm}^{-2}$ & $1145 \mathrm{mAh} \mathrm{g}^{-1}$ & $1034 \mathrm{mAh} \mathrm{g}^{-1}$ \\
\hline $10 \mathrm{mAh} \mathrm{cm}^{-2}$ & $1265 \mathrm{mAh} \mathrm{g}^{-1}$ & $1123 \mathrm{mAh} \mathrm{g}^{-1}$ \\
\hline
\end{tabular}

Calculation of the specific capacity of composite anodes with CF and N-CF host

$$
\mathrm{b}_{g}=\frac{Q}{m}
$$

where the $b_{g}$ is specific capacity, the $Q$ is quantity of electric charge and the $m$ is the weight of composite.

Combining the theoretical specific capacity of Li metal $(3860 \mathrm{mAh} / \mathrm{g})$ and the mass of $\mathrm{CF}$ or $\mathrm{N}-\mathrm{CF}$, the specific capacity of composite anode when depositing different amounts of Li metal can be calculated, the results are shown in Table S2. 
Table S3. The mass content of different element in N-CF current collector.

\begin{tabular}{ll}
\hline & Mass content $/ \%$ \\
\hline $\mathbf{C}$ & 76.480 \\
$\mathbf{H}$ & 6.093 \\
$\mathbf{S}$ & 2.338 \\
\hline
\end{tabular}

Table S4. The voltage delay of CF and N-CF current collector at different cycles

\begin{tabular}{ccc}
\hline 1st & CF & N-CF \\
\hline 10th & $36 \mathrm{mv}$ & $29 \mathrm{mv}$ \\
20th & $94 \mathrm{mv}$ & $72 \mathrm{mv}$ \\
30th & $108 \mathrm{mv}$ & $74 \mathrm{mv}$ \\
40th & $111 \mathrm{mv}$ & $74 \mathrm{mv}$ \\
\hline
\end{tabular}

